Supplement of Clim. Past Discuss., 11, 5345-5399, 2015

http://www.clim-past-discuss.net/11/5345/2015/

doi:10.5194/cpd-11-5345-2015-supplement

(C) Author(s) 2015. CC Attribution 3.0 License.

(c) (i)

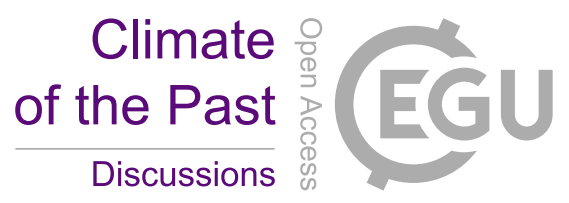

Supplement of

\title{
Effects of melting ice sheets and orbital forcing on the early Holocene warming in extratropical Northern Hemisphere
}

\section{Y. Zhang et al.}

Correspondence to: Y. Zhang (yurui.zhang@ @elsinki.fi)

The copyright of individual parts of the supplement might differ from the CC-BY 3.0 licence. 
Figure S1 Domain of selected region (Arctic, NW Europe, N Canada, Alaska and Siberia) denoted by the rectangle.

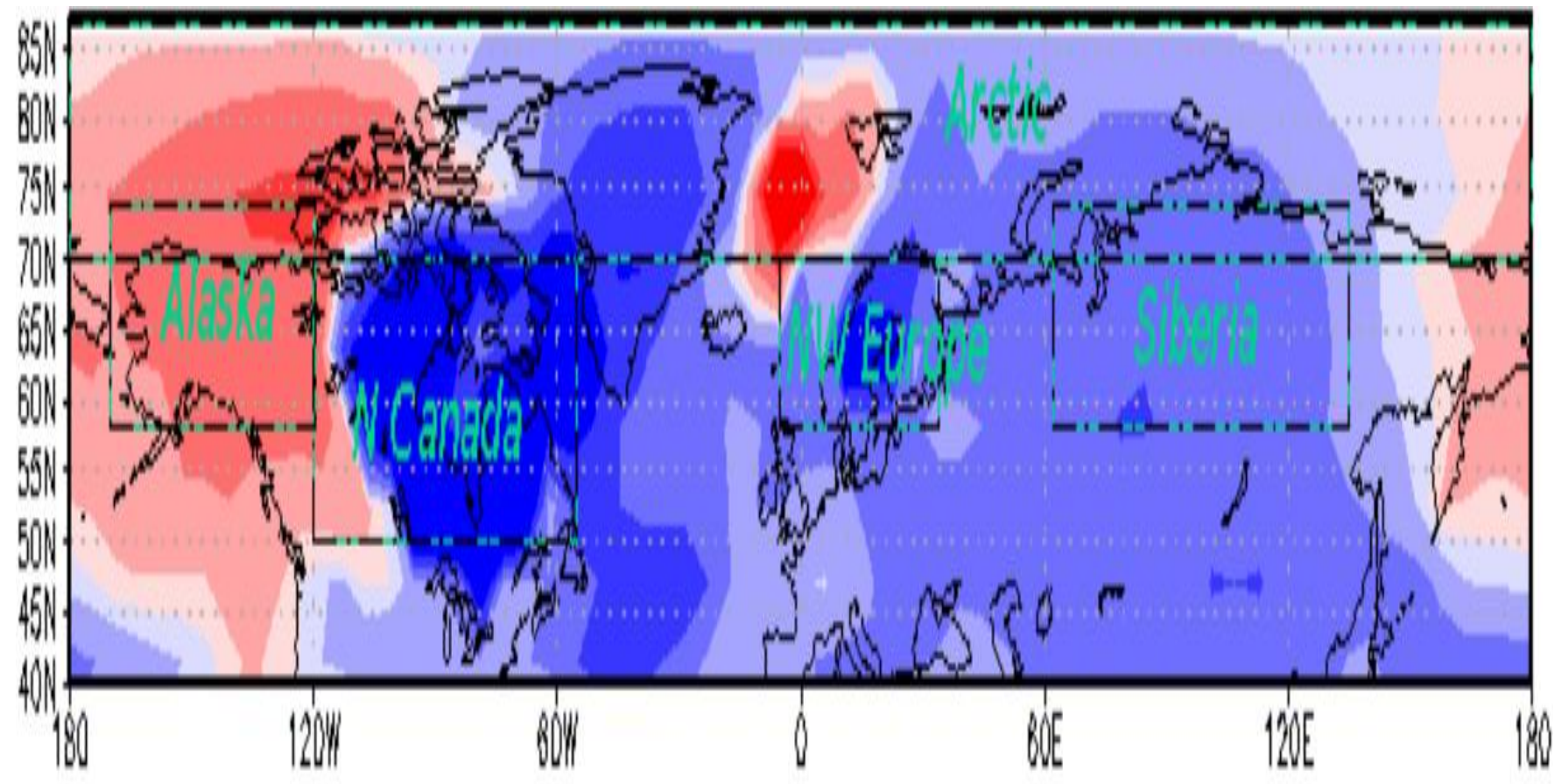

